\section{Jobmaschine für Bremen}

Welche Bedeutung hat die Sozialwirtschaft für das Land Bremen? Wie viele Menschen arbeiten in sozialen Betrieben und welche Wertschöpfung produziert die Sozialwirtschaft?

Zum ersten Mal wurden diese Fragestellungen für das Bundesland Bremen wissenschaftlich untersucht. Für den Paritätischen Wohlfahrtsverband Bremen, den Auftraggeber der hier vorgestellten BASYS-Studie, ist die objektive Analyse der wirtschaftlichen und fiskalischen Effekte der Sozialwirtschaft besonders wichtig. Denn - so die Meinung des Paritätischen - die Bedeutung der Sozialwirtschaft und der Arbeit der Wohlfahrtsverbände für das bremische Gemeinwesen wird in der Regel unterschätzt. Ausgaben für den Sozialbereich werden oft nur als Kosten gesehen.

Die Sozialwirtschaft ist eine Branche mit Wachstumsperspektiven. Aktuell sind in Bremen circa 26.500 Personen in der Sozialwirtschaft beschäftigt, also rund sieben Prozent aller Erwerbstätigen. Zusätzlich sind rund 10.000 Beschäftigte in Bereichen tätig, die indirekt von der Sozialwirtschaft abhängen. Fiskalische Effekte verbinden sich mit Arbeitsmarkteffekten. Je mehr Einwohner durch soziale Dienstleistungen an den Wohnort Bremen und Bremerhaven gebunden werden können, desto höher sind die Einnahmen im Rahmen des Finanzausgleichs an die bremischen Haushalte und desto mehr Arbeitsplätze werden geschaffen.

64 Prozent der sozialwirtschaftlichen Produktionswerte werden aus Landesmitteln und Mitteln der Kommunen Bremen und Bremerhaven finanziert, 36 Prozent werden vom Bund, der Sozialversicherung und den privaten Haushalten finanziert. Das bedeutet: Durch die eingesetzten Bremer Mittel werden erhebliche Mittel von anderen Stellen gebunden und eingeworben. Und die Ausgaben für sozialwirtschaftliche Leistungen erwirtschaften Steuereinnahmen.

Der Paritätische Bremen hat immer wieder dafür plädiert, dass bremische Senioren auch in bremischen Pflegeheimen betreut werden oder dass Kinder, die nicht von ihren Eltern versorgt werden können, ein Angebot in Bremen finden, dass Plätze und Angebote in Bremen geschaffen werden müssen. Die BASYS-Studie zeigt, dass sozial Notwendiges auch ökonomisch sinnvoll ist. Ihre Ergebnisse werden in der politischen Auseinandersetzung mit Kostenträgern sowie dem Sozial,- Wirtschafts- und Finanzressort genutzt werden im Interesse von Klienten, Mitarbeitern und Anbietern von sozialen Dienstleistungen und im Interesse des bremischen Gemeinwesens.

Wolfgang Luz

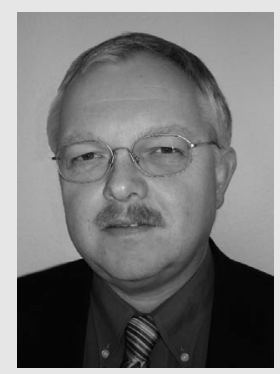

Wolfgang Luz ist hauptamtlicher Vorstand des Paritätischen Wohlfahrtsverbandes in Bremen. E-Mailw.luz@paritaet-bremen.de

\section{Gutes Geld}

\section{für gute Zwecke}

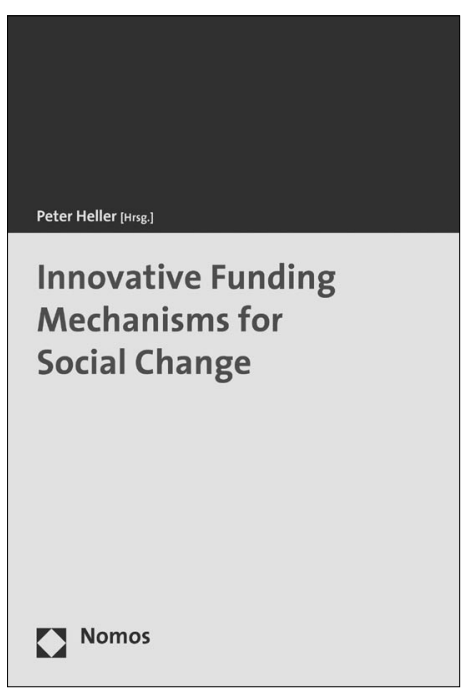

\section{Innovative Funding Mechanisms for Social Change}

Herausgegeben von Dr. Peter W. Heller

2009, 144 S., brosch., 24,- $€$, ISBN 978-3-8329-3948-9

Wo die soziale Sicherung des Staates versagt, finden Gemeinwohl-Unternehmer Lösungen, aber ihnen fehlen oft die notwendigen finanziellen Mittel. Die Beiträge in diesem Buch analysieren marktwirtschaftliche Finanzierungsmodelle, die auf neuen Wegen soziales Wagniskapital mobilisieren.

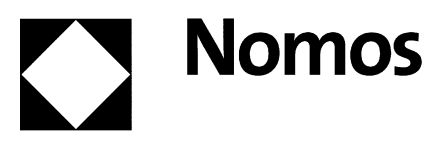

Bitte bestellen Sie im Buchhandel oder versandkostenfrei unter $\boldsymbol{v}$ www.nomos-shop.de 